\title{
Características Morfocuantitativas de la Glándula Submandibular de Ratón (Mus musculus)
}

\author{
Morphocuantitative Characteristics of the Mouse (Mus musculus) Submandibular Gland
}

Juan Ocampo ${ }^{1,2}$; Bélgica Vásquez ${ }^{3}$; Cristian Sandoval ${ }^{4}$; Javiera Navarrete" ${ }^{1}$ Ziyad S. Haidar ${ }^{5,6} \&$ Sergio Olate $^{7,8}$

OCAMPO, J.; VÁSQUEZ, B.; SANDOVAL, C.; NAVARRETE, J.; HAIDAR, Z. S. \& OLATE, S. Características morfocuantitativas de la glándula submandibular de ratón (Mus musculus). Int. J. Morphol., 38(3):570-577, 2020.

RESUMEN: El ratón (Mus musculus) es un buen modelo animal de experimentación, donde sus glándulas salivales han sido utilizadas en estudios, especialmente de tipo preclínico. Sin embargo, las diferencias en la morfología de estas glándulas y, en particular de las submandibulares, entre humanos y roedores no son de conocimiento común. Por lo anterior, el objetivo de este estudio fue conocer las características morfocuantitativos de la glándula submandibular del ratón macho C57BL/6. Se utilizaron cinco ratones macho, cepa C57BL/ 6, de 11 a 13 semanas de nacidos, con un peso promedio de $30 \mathrm{~g}$. Luego de su ambientación, los ratones fueron eutanasiados. Para el análisis histológico, las glándulas fueron extraídas y fijadas en formalina tamponada por 48 horas, procesada para su inclusión en paraplast y teñidas con hematoxilina y eosina, azul alcián pH 2,5, ácido peryódico de Schiff y Picrosirius Red. Se determinaron las características estereológicas de densidad de longitud $\left(\mathrm{L}_{\mathrm{V} \text { cond }}\right)$, de volumen $\left(\mathrm{V}_{\mathrm{V} \text { cond }}\right)$ y de superficie $\left(\mathrm{S}_{\mathrm{V} \text { cond }}\right)$ de los conductos. En las células acinares se evaluó la densidad de número $\left(\mathrm{N}_{\mathrm{vcel}}\right)$ y la densidad de volumen $\left(\mathrm{V}_{\mathrm{Vcel}}\right)$. Para cada variable se obtuvo la media \pm desviación estándar. La glándula submandibular se encontraba organizada de manera lobulada, cuyo parénquima era de tipo túbuloacinar mixto con predominio seroso, que se conectaba a través de conductos. Las células acinares presentaban reacción positiva para azul alcián y ácido peryódico de Schiff. El estroma de la glándula contenía principalmente colágeno tipo 1. Los resultados de las mediciones estereológicas fueron: $\mathrm{L}_{\mathrm{Vcond}}=220,02 \pm 50,51 \mathrm{~mm} / \mathrm{mm}^{3} ; \mathrm{V}_{\mathrm{Vcond}}=$ $50,48 \pm 9,55 \% ; \mathrm{S}_{\mathrm{V}_{\text {cond }}}=26,39 \pm 5,45 \mathrm{~mm}^{2} / \mathrm{mm}^{3} ; \mathrm{N}_{\mathrm{Vcel}}=16,85 \times 104 \pm 9,13 \times 10^{4} / \mathrm{mm}^{3} ; \mathrm{V}_{\mathrm{Vcel}}=24,98 \pm 6,22 \%$. Con los análisis presentados es posible realizar investigaciones experimentales, considerando las similitudes y diferencias morfocuantitativas que presenta la glándula submandibular de ratón macho, cepa C57BL/6 con la del humano.

PALABRAS CLAVE: Glándula submandibular; Ratón; Histología; Análisis morfocuantitativo; Estereología.

\section{INTRODUCCIÓN}

Los estudios preclínicos experimentales necesitan de modelos animales de prueba que sean fiables, que puedan validar los resultados de las terapias empleadas en seres humanos, aún antes de su desarrollo y aplicación en estos últimos (Nilsson et al., 2012). Más del $99 \%$ de los genes de ratón tienen contraparte humana. Los ratones C57BL/6, también llamados "C57 black 6" o simplemente "Black 6", poseen las ventajas de estabilidad de cepa y fácil crianza. Este, también es el primer ratón cuyo genoma fue secuenciado por completo en el año 2005, luego del genoma humano (Beura et al., 2016). El Consorcio Internacional de Fenotipificación del Ratón (International Mouse Phenotyping ConsortiumIMPC), lanzó, el 29 de septiembre de 2011, una iniciativa para catalogar la función de cada gen del ratón de esta cepa, utilizando tecnologías de deleción génica.

Los ratones $\mathrm{C} 57 \mathrm{BL} / 6$ han sido empleados en tres áreas principales. La más común es servir como modelo fisiológico o patológico en experimentos in vivo, por ejemplo, Louveau et al. (2015), utilizando ratones C57BL/6, descubrieron vasos linfáticos del sistema nervioso central; en segundo lugar, se los suele utilizar para construir ratones modelo transgénicos; por último, estos ratones se utilizan como cepa de fondo genético para la generación de congénicos con mutaciones espontáneas o inducidas (Mahajan et al., 2016).

\footnotetext{
${ }^{1}$ Programa de Doctorado en Ciencias Morfológicas, Universidad de La Frontera, Temuco, Chile.

${ }^{2}$ Cátedra de Histología Normal, Carrera de Medicina, Universidad Central del Ecuador, Quito, Ecuador.

${ }^{3}$ Universidad de Tarapacá, Arica, Chile.

${ }^{4}$ Departamento de Ciencias Preclínicas, Facultad de Medicina, Universidad de La Frontera, Temuco, Chile.

${ }^{5}$ BioMATX, Facultad de Odontología, Universidad de Los Andes, Santiago, Chile.

${ }^{6}$ Center for Biomedical Research and Innovation (CIIB), Faculty of Medicine, Universidad de Los Andes, Santiago, Chile.

${ }^{7}$ Centro de Excelencia en Estudios Morfológicos y Quirúrgicos (CEMyQ), Universidad de La Frontera, Temuco, Chile.

${ }^{8}$ División de Cirugía Oral, Facial y Maxilofacial, Facultad de Odontología, Universidad de La Frontera, Temuco, Chile.
} 
Desde hace décadas se han realizado investigaciones acerca del desarrollo, estructura y función de las glándulas salivales de mamíferos y sus semejanzas con las humanas (Denny et al., 1997, Roa \& del Sol, 2019). Es muy frecuente el uso de modelos murinos para el análisis de la acción de ciertas sustancias en glándulas salivales (Mattioli et al., 2016). Los ratones han tenido bastante cabida en los estudios que intentan encontrar nuevos tratamientos de prevención o curación para la hiposialia y xerostomía, las cuales constituyen efectos adversos graves que sobrevienen posteriormente a la radioterapia administrada contra neoplasias de cabeza y cuello, como producto de una lesión colateral importante de las glándulas salivales (Ocampo et al., 2019).

Las glándulas salivales mayores, tanto humanas como murinas, son tres pares de glándulas: parótida, submandibular y sublingual y, en conjunto, producen el $95 \%$ de la saliva (Amano et al., 2012). Mientras que la glándula submandibular humana, por sí sola, se encarga de secretar el 65 - 70 $\%$ de esta, las glándulas menores, aunque numerosas, no logran sobrepasar el 5 - $10 \%$ de la producción salival (Carlson \& Ord, 2015).

Según Vucicevic-Boras et al. (2001), el principal rol de la saliva es mantener un balance ecológico en la cavidad oral. No obstante, tiene también funciones sistémicas que se relacionan directamente con la calidad de vida de la persona, como son, digestión, respiración, fonación, gusto, entre otras (Dawes et al., 2015).

En ratones, la glándula submandibular es la de mayor tamaño. Está ubicada en la línea media ventral del cuello, donde las glándulas derecha e izquierda están opuestas y se extienden hacia el esternón; está limitada, rostralmente, por el linfonodo submandibular, donde también linda con la glándula sublingual. La glándula parótida se extiende lateral y dorsalmente a ellas. Una diferencia importante entre la glándula submandibular de humanos y ratones es que en los primeros la glándula más voluminosa es la parótida (Treuting et al., 2018).

Desde el punto de vista histológico, la glándula submandibular humana es de tipo mixto, observándose adenómeros mucosos y, en mayor cantidad, serosos, además de semilunas serosas, estas últimas muy desarrolladas y que rodean a los adenómeros mucosos (Suazo \& Roa, 2008). Los adenómeros son de forma acinar, es decir, redondeada, vistos desde afuera. Las células acinares serosas y mucosas son de forma piramidal, de ápice truncado y base periférica, dirigida hacia la membrana basal epitelial; difieren en la forma de sus núcleos, los cuales son redondos en las serosas y aplanados en las mucosas; también divergen en cuanto al color del citoplasma teñido con hematoxilina y eosina (H\&E), pues este es basófilo en la base y acidófilo en el ápice en las células serosas, mientras que las mucosas prácticamente no adoptan los colorantes indicados (de Paula et al., 2017).

Su sistema de conductos comienza en el propio acino, continúa con el conducto intercalado, el cual drena en el conducto estriado. Ambos son intralobulillares, siendo el primero mucho más pequeño, de células cúbicas y núcleo central; por su parte, el segundo es más grande, está formado por células cilíndricas acidófilas y de núcleo ubicado en la región apical. Estos conductos, juntamente con los adenómeros acinares, elaboran saliva, es decir, reciben la saliva primaria de los adenómeros y terminan modificándola para convertirla, finalmente, en saliva definitiva (Treuting et al.). Además, producen una gran cantidad de factores de crecimiento, polipéptidos, enzimas, inmunoglobulinas y otras sustancias bioactivas, como parte de su secretoma, las cuales pasan a la saliva o al torrente circulatorio, según sea el caso (Ocampo et al.) y han sido descritas desde hace varias décadas (Korsrud \& Brandtzaeg, 1982), inclusive en otros vertebrados (Gresik, 1994). Luego encontramos a los conductos excretores de mayor tamaño, macroscópicos, y conducen la saliva, sin modificarla, al interior de la cavidad oral (Amano et al.).

Las características histológicas de la glándula submandibular del ratón son un poco diferentes a las de la humana. Los adenómeros son acinos de naturaleza serosa, conformados por células grandes y basófilas, con abundantes gránulos de cimógeno en su zona apical y también con pequeñas gotas de mucina, lo que la vuelve mixta, con predominio seroso (Treuting et al.). Respecto a sus conductos, la principal divergencia con la glándula humana es la presencia, en ratones, del conducto contorneado granuloso, localizado entre el conducto intercalado y el estriado, y cuyas células presentan una gran cantidad de gránulos que contienen factores de crecimiento, hormonas y otros péptidos biológicamente activos (Mori et al., 1992; Gresik et al., 1996). Estos conductos se observan numerosos, voluminosos y de coloración más intensa en el ratón macho, debido a un dimorfismo sexual dependiente de testosterona (Sato et al., 1994). Los adenómeros y el inicio de los conductos que parten de ellos, tanto en glándulas submandibulares humanas como de ratones, tienen, células mioepiteliales situadas entre la base de las células y la membrana basal epiteliales (Carlson \& Ord).

Existen distintos métodos y técnicas que permiten estudiar las características morfocuantitativas de tejidos y órganos. La estereología es una herramienta interdisciplinaria que se encarga de la interpretación tridimensional de secciones planas de materiales o tejidos, es decir, se internaliza en la disposición tridimensional de las estructuras, partien- 
do de su información en dos dimensiones. Se ayuda de nociones geométricas y estadísticas para conseguir su propósito. Además de arrojar resultados numéricos -absolutos y relativos-, objetivos y reproducibles, permite comparaciones más reales, las cuales son sujeto de ser probadas. $\mathrm{Su}$ fortaleza más llamativa es la capacidad de corresponder morfología y función, mediante relaciones bien direccionadas (Mandarim-de-Lacerda \& del Sol, 2017).

En concordancia con la vigencia de la utilización de ratones -C57BL/6- como modelos animales de experimentación, su empleo en el estudio de las glándulas salivales, y la necesidad de conocer más acerca de sus perspectivas en este tema, se ha realizado el presente trabajo de investigación, con el objetivo de obtener datos morfocuantitativos de la glándula submandibular del ratón C57BL/6, para así comprender, de mejor manera, su morfología y función y sentar las bases para futuros estudios experimentales.

\section{MATERIAL Y MÉTODO}

Se utilizaron cinco ratones macho (Mus musculus), cepa C57BL/6, de 11 a 13 semanas de nacidos, con un peso promedio de $30 \mathrm{~g}$, provenientes del Instituto de Salud Pública de Chile. Para su adaptación al nuevo entorno, los animales permanecieron siete días en el Bioterio del Centro de Excelencia en Estudios Morfológicos y Quirúrgicos (CEMyQ) de la Universidad de La Frontera a una temperatura de $22 \pm 2{ }^{\circ} \mathrm{C}$ con humedad controlada y un ciclo de luz/ oscuridad de 12 h (08:00 h - 20:00 h / 20:00 h - 08:00 h); durante su permanencia fueron mantenidos con dieta estándar de laboratorio (AIN-93M) (Reeves et al., 1993) y agua $a d$ libitum. Para la realización del estudio, se consideraron las directrices establecidas en la Guía para el Cuidado y Uso de Animales de Laboratorio (2011). Este estudio fue aprobado por el Comité Ético Científico de Universidad de La Frontera $\left(\mathrm{N}^{\circ} 025 / 2016\right)$.

Eutanasia y obtención de las glándulas submandibulares. Los animales fueron eutanasiados con sobredosis de $60 \mathrm{mg} /$ $\mathrm{kg}$ de ketamina y $8 \mathrm{mg} / \mathrm{kg}$ de xilacina, luego de un ayuno de 6 horas. Para la extracción de las muestras, se realizó una incisión mediana submentoesternal, que incluyó la fascia anterior del cuello. Luego, fueron fijadas en formalina tamponada $(1,27 \mathrm{~mol} / \mathrm{L}$ de formaldehído en tampón fosfato $0,1 \mathrm{M} \mathrm{pH} \mathrm{7,2)} \mathrm{al} 4 \%$ durante 48 horas.

Análisis morfocuantitativo. Posterior a su fijación, las muestras fueron deshidratadas, y embebidas en Paraplast Plus (Sigma-Aldrich Co., St. Louis, MO, EE. UU.). Una vez obtenidos los bloques, se realizaron cortes de $5 \mu \mathrm{m}$ de espesor (Leica® RM2255) y fueron teñidos con hematoxilima eosina (H \& E), Picrosirius Red F3BA 0,1\% p/v (Sigma-Aldrich Co., St. Louis, MO, EEE. UU.), azul alcián (AA) a pH 2,5 y ácido peryódico de Schiff (PAS), para su posterior análisis histológico y estereológico.

El estudio estereológico consideró los conductos glandulares y las células acinares de la glándula submandibular. A nivel de los conductos se analizaron seis campos aleatorios por animal, observando en total 30 campos (Mandarim-deLacerda \& del Sol). Mientras que, para el estudio estereológico de las células acinares se analizaron 22 campos aleatorios por animal, observando un total de 110 campos. Las láminas fueron visualizadas bajo un microscopio estereológico Leica ${ }^{\circledR}$ DM2000 LED, fotografiadas con cámara digital Leica ${ }^{\circledR}$ MC170 HD y analizadas utilizando el sistema de prueba de 36 puntos diseñado por STEPanizer®.

En los conductos glandulares se determinó la densidad de longitud ( $\left.\mathrm{L}_{\mathrm{V} \text { cond }}\right)$, la densidad de volumen $\left(\mathrm{V}_{\mathrm{V} \text { cond }}\right)$ y la densidad de superficie $\left(\mathrm{S}_{\mathrm{V} \text { cond }}\right)$. La $\mathrm{L}_{\mathrm{V} \text { cond }}$ fue determinada considerando la siguiente ecuación: $\mathrm{L}_{\mathrm{Vcond}}=2 \mathrm{x} \mathrm{N}_{\text {Acond }}$; donde $\mathrm{N}_{\text {Acond }}=\mathrm{N} / \mathrm{A}_{\mathrm{T}}$ y $\mathrm{N}$ corresponde al número de observaciones en un área determinada considerando las líneas prohibidas, $\mathrm{A}_{\mathrm{T}}$ es el área total del sistema de prueba. $\mathrm{La} \mathrm{V}_{\mathrm{V} \text { cond }}$ fue evaluada utilizando la siguiente fórmula: $\mathrm{V}_{\mathrm{Vcond}}=\mathrm{P}_{\text {Pcond }} / \mathrm{P}_{\mathrm{T}}$ $(100 \%)$, donde $\mathrm{P}_{\text {Pcond }}$ es el número de puntos que tocan los conductos y $\mathrm{P}_{\mathrm{T}}$ el número total de puntos sistema. La $\mathrm{S}_{\mathrm{V}_{\text {cond }}}$ fue determinada según la siguiente fórmula: $\mathrm{S}_{\mathrm{V}_{\text {cond }}}=(2 \times \mathrm{I}) /$ $\mathrm{L}_{\mathrm{T}}$, donde I es el número de intersecciones que tocan la estructura y $\mathrm{L}_{\mathrm{T}}$ es la longitud total de las líneas del sistema de prueba.

En las células acinares se evaluó la densidad de número $\left(\mathrm{N}_{\mathrm{Vcel}}\right)$ y la densidad de volumen $\left(\mathrm{V}_{\mathrm{Vcel}}\right)$. La $\mathrm{N}_{\mathrm{Vcel}}$ se determinó según la siguiente ecuación: $\mathrm{N}_{\mathrm{Vcel}}=\mathrm{Q}-/\left(\mathrm{A}_{\mathrm{T}} \times \mathrm{t}\right)$, donde $\mathrm{Q}^{-}$es el número de observaciones en un área determinada considerando las líneas prohibidas y el plano prohibido, $\mathrm{A}_{\mathrm{T}}$ es el área total del sistema de prueba y t es el grosor del disector.

Se realizó un análisis estadístico descriptivo de las variables de interés. Para cada variable se obtuvo la media \pm desviación estándar.

\section{RESULTADOS}

Los ratones poseen tres glándulas salivales principales emparejadas que son visibles de forma macroscópica: sublingual, submandibular y parótida y numerosas glándulas menores microscópicas (Fig. 1). 


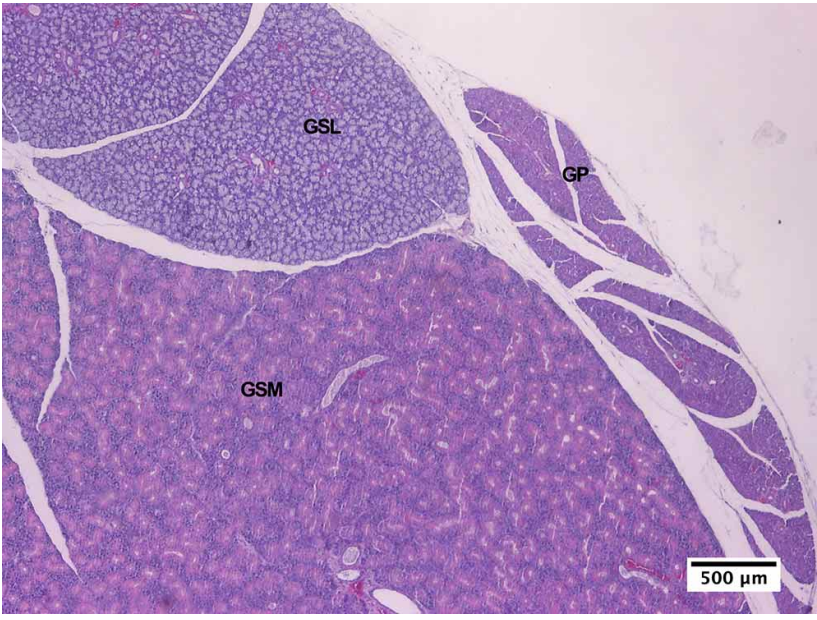

Fig. 1. Glándulas salivales de ratón macho C57BL/6. Glándula sublingual (GSL), glándula submandibular (GSM), glándula parótida (GP). Tinción H \& E.

Las glándulas submandibulares, se encuentran organizadas de manera multilobada y lobulada. El parénquima es de tipo túbuloacinar mixto, con predominio seroso, que se conecta a través de conductos.

En el ratón macho, la secreción glandular es excretada a través de una serie de conductos, cuyos diámetros van de menor a mayor tamaño. Inicialmente, la secreción es excretada por los conductos intercalados, luego a través de los conductos contorneados granulosos, conductos estriados, $\mathrm{y}$, finalmente, a través de los conductos interlobulares. Estos últimos se fusionan en conductos excretores que desembocan en la cavidad oral.

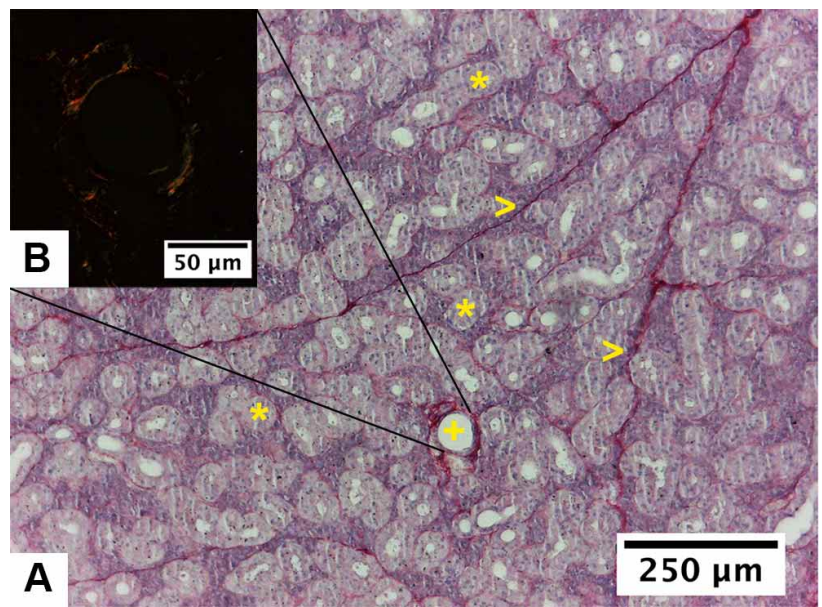

Fig.2. Glándula submandibular de ratón macho C57BL/6. Se observa tejido glandular tipo túbuloacinar. Los conductos contorneados granulosos (*) y los conductos estriados (+) se encuentran rodeados por tejido conectivo (>) con fibras colágenas tipos I (roja o amarilla) y III (verde). A. Tinción H \& E. B. Picrosirius Red.
Los conductos más abundantes y de distribución homogénea en el parénquima glandular son los conductos contorneados granulosos. Los conductos estriados son menos frecuentes y se caracterizaban por presentar mayor lumen y tejido conectivo a su alrededor (Fig. 2). Los conductos contorneados granulosos se encuentran revestidos por células voluminosas de tipo columnar que contienen prominentes gránulos eosinófilos. Los conductos estriados se encuentran revestidos por epitelio simple cúbico, cuyas células presentan núcleos de ubicación central (Fig. 3).

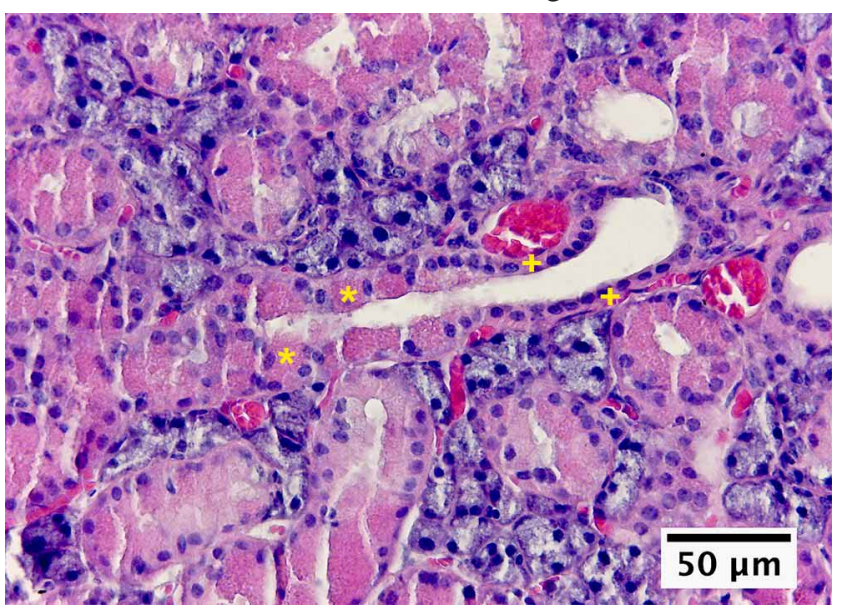

Fig. 3. Glándula submandibular de ratón macho C57BL/6. Tejido glandular tipo túbuloacinar. Se destacan prominentes conductos contorneados granulosos (*) y conducto estriados (+). Tinción H \& E.

En el tejido glandular, las células acinares seromucosas presentan un aspecto piramidal, con una superficie basal amplia y núcleos redondos. La zona basal del citoplasma presenta basofilia con la tinción de H\&E. El citoplasma con gránulos de mucinógeno se tiñe levemente con esta tinción (Fig. 4).

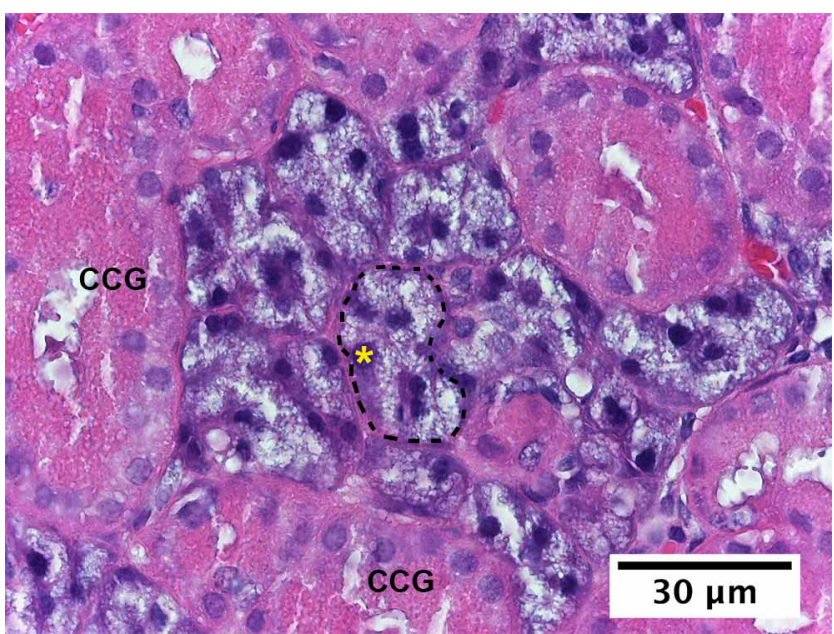

Fig. 4. Glándula submandibular de ratón macho C57BL/6. Parénquima glandular túbuloacinar de tipo mixto, con predominio seroso. Se observa la presencia de acinos glandulares (líneas punteadas), célula seromucosa $(*)$ y conductos contorneados granulosos (CCG). Tinción H \& E. 

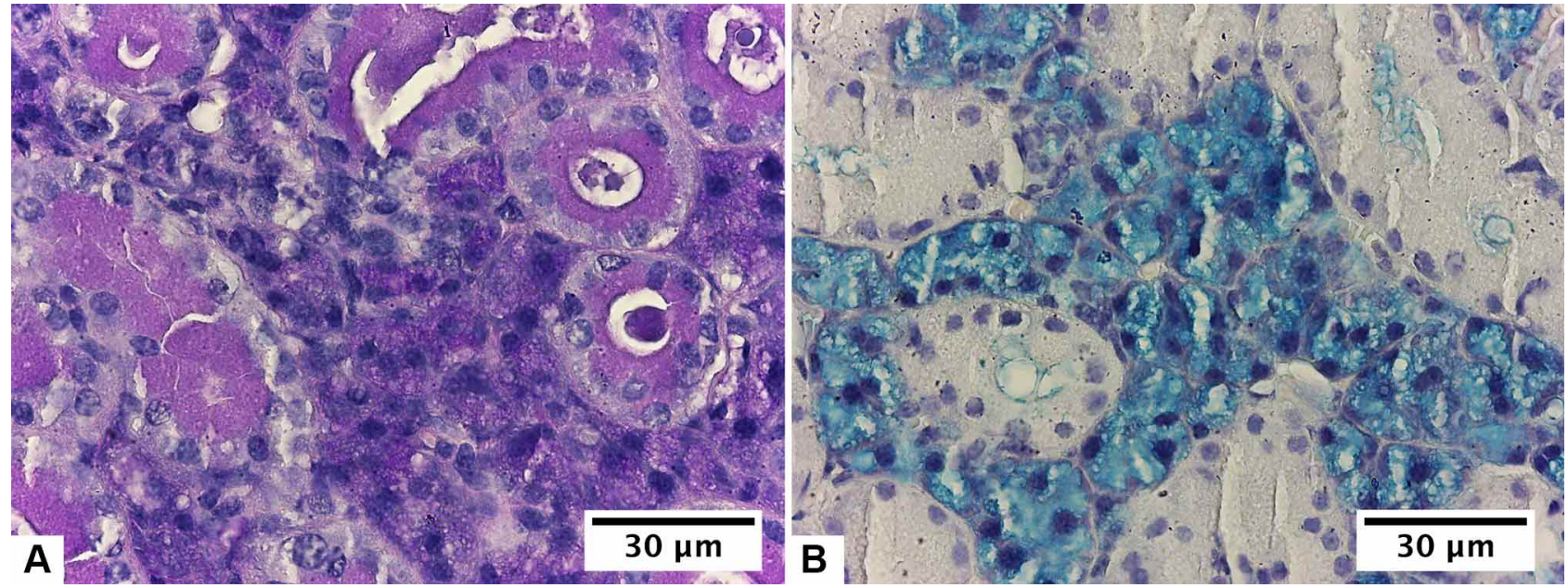

Fig. 5. Glándula submandibular de ratón macho C57BL/6. A. Se observa la presencia de mucopolisacáridos neutros en el tejido glandular y producto de secreción, tinción PAS. B. Se observa la presencia de mucopolisacáridos ácidos en el tejido glandular y producto de secreción. Tinción AA pH 2,5.

La coloración con PAS y AA pH 2,5 evidencia la presencia de mucopolisacáridos neutros y ácidos, respectivamente, en el tejido glandular y productos de secreción. Sin embargo, las células de los conductos excretores no mostraron reacción positiva (Fig. 5).

El análisis estereológico de los conductos glandulares, así como de las células acinares, se presenta en la Tabla I.

Tabla I. Análisis estereológico de los conductos excretores y células acinares de la glándula submandibular de ratón C57BL/6.

\begin{tabular}{lc}
\hline Parámetros estereológicos & Media \pm DS \\
\hline $\mathrm{L}_{\mathrm{V}_{\text {cond }}}\left(\mathrm{mm} / \mathrm{mm}^{3}\right)$ & $220,02 \pm 50,51$ \\
$\mathrm{~V}_{\mathrm{V} \text { cond }}(\%)$ & $50,48 \pm 9,55$ \\
$\mathrm{~S}_{\mathrm{V}_{\text {c ond }}}\left(\mathrm{mm}^{2 /} \mathrm{mm}^{3}\right)$ & $26,39 \pm 5,45$ \\
$\mathrm{~N}_{\mathrm{Vcel}}\left(\mathrm{x} 10^{4 /} \mathrm{mm}^{3}\right)$ & $16,85 \pm 9,13$ \\
$\mathrm{~V}_{\mathrm{Vcel}}(\%)$ & $24,98 \pm 6,22$ \\
\hline
\end{tabular}

\section{DISCUSIÓN}

Las investigaciones clínicas y patológicas requieren conocer la anatomía y la histología de los tejidos humanos; por otro lado, también es de interés la morfología normal y/ o el uso funcional de animales para tratamientos y procedimientos experimentales. Las limitaciones técnicas y bioéticas con respecto al manejo de los tejidos humanos, así como los avances en los estudios analíticos genéticos con animales nokout, han aumentado la necesidad de una buena comprensión de los tejidos de los animales experimentales, especialmente de los roedores. Por lo tanto, para los investigadores clínicos existe la necesidad de un conocimiento más amplio sobre las glándulas salivales de humanos y roedores (Louveau et al.; Mahajan et al.). En este sentido, nuestro estudio ha permitido conocer algunas de las características morfocuantitativas más relevantes de la glándula submandibular del ratón macho C57BL/6 adulto.

Las glándulas salivales de roedores, utilizadas en experimentos con animales, muestran algunas diferencias histológicas con las glándulas humanas. Especialmente, las glándulas submandibulares de roedores, ya que desarrollan conductos contorneados granulosos productores de una variedad de factores de crecimiento celular (Amano et al.), que incluyen EGF, NGF (Mori et al.; Gresik et al.), BDNF (Kondo et al., 2010), HGF (Amano \& Iseki, 2001; Amano, 2011), IGF (Amano \& Iseki, 2001); TGF-a (Wu et al., 1993) y TGF-b (Amano), los cuales son secretados de manera exocrina. Las glándulas submandibulares humanas, por otro lado, no tienen túbulos contorneados granuosos (Pinkstaff, 1998; Chen et al., 1995; Gresik; Gresik et al.). Sin embargo, también secretan factores de crecimiento a partir de porciones distintas dentro de las glándulas (Lantini et al., 2006).

Otro aspecto importante de considerar a la hora de escoger el modelo animal, es el dimorfismo sexual que presenta la glándula submandibular en roedores. Como fue mencionado, los conductos contorneados granulosos se encuentran poco desarrollados en las hembras debido a la falta de influencia de las hormonas sexuales masculinas, como la testosterona (Sato et al.; Pardini \& Taga,1996; Amano \& Iseki, 2005). Además, el dimorfismo sexual de la glándula submandibular del ratón es más prominente que el de la glándula de la rata (Amano et al.). 
Por otra parte, investigaciones han demostrado que la edad y las variaciones estacionales producen cambios estructurales y funcionales en los conductos contorneados granulosos de la glándula submandibular en roedores. Al respecto, Sashima (1986) advirtió la regresión de la extensión y altura de los conductos contorneados granulosos y del contenido de sus gránulos, a medida que avanzaba la edad. De Asis et al. (2000), demostraron que durante el invierno y entre la noche y la madrugada, existía una disminución del peso y del volumen de los acinos y conductos excretores, y crecimiento del estroma, mayoritariamente marcada que durante el verano. Nuestro estudio, solo consideró el análisis morfocuantitativo de las glándulas submandibulares de ratones adultos y en un momento determinado, en época de invierno. Creemos necesario continuar indagando al respecto para comprender de mejor manera los mecanismos biológicos involucrados en los cambios estructurales y funcionales de la glándula submandibular en este modelo en específico.

En relación con las características histológicas de los acinos que constituyen la glándula submandibular de ratón macho C57BL/6, podemos señalar que nuestro estudio corrobora lo observado en otras especies de roedores como las ratas (Amano et al.), es decir, la glándula submandibular se encuentra constituida por acinos seromucosos, con presencia de mucopolisacáridos neutros y ácidos en el interior de sus células. Existen algunos estudios experimentales en ratas que han demostrado cambios morfológicos en la arquitectura de los acinos glandulares tras la inducción de hipotiroidismo (Noorafshan, 2001) y diabetes (Noorafshan, 2006), evidenciando, en ambos casos, disminución del volumen acinar.

Respecto a la estereología, al comparar nuestros resultados con aquellos obtenidos en otras investigaciones realizadas en glándulas submandibulares de rata, podemos observar ciertas diferencias. Por ejemplo, en lo que respecta a la $\mathrm{V}_{\mathrm{v}}$, Mahmoudzadeh-Sagheb et al. (2006) encontraron que los acinos ocupaban el 53,04 $\pm 1,30 \%$ de la glándula de ratas Wistar macho, y los conductos intralobulares, alrededor del 31,30\%. En nuestro estudio obtuvimos una $\mathrm{V}_{\mathrm{V}}$ de $24,98 \pm 6,22 \%$ para los acinos y de 50,48 $\pm 9,55 \%$ para los conductos. La discordancia aquí expuesta puede deberse a la diferencia entre especies, ya que estudios realizados por Flavia et al. (2017) en ratones machos albinos, reportaron resultados similares a los nuestros en relación a la $\mathrm{V}_{\mathrm{V}}$ de los conductos excretores $(59,21 \%)$. Además, en este mismo estudio, se comparó el área y el volumen de los conductos estriados y contorneados granulosos de glándulas submandibulares, entre ratones albinos y ratas macho, encontrándose valores mayores para los conductos estriados, en ratas, y para los conductos contorneados granulosos, en ratones.
Asimismo, nuestros resultados son comparables con otros realizados en ratones macho. Jacob \& Lawrence (1989), encontraron una $\mathrm{V}_{\mathrm{v}}$ de $29,4 \pm 1,72 \%$ para acinos y de 61,03 $\pm 2,24 \%$ para conductos, en ratones Swiss, muy similares a los aquí expuestos $\left(\mathrm{V}_{\mathrm{v}}\right.$ de 24,98 \pm 6,22 \% para los acinos y de 50,48 \pm 9,55\% para los conductos). Pardini \& Taga (1996), por otra parte, también están muy cerca de estas mediciones, encontrando una $\mathrm{V}_{\mathrm{v}}$ de acinos de 24,6 $6 \pm 0,44 \%$ y de conductos aproximadamente de $58,2 \%$ en ratones albinos.

Mediante la estereología, también se han detectado cambios sustanciales en varios trabajos clínicos, en los que se ha intervenido a los modelos animales de experimentación, induciendo estados no fisiológicos como el hipotiroidismo, la diabetes, o también la menopausia. En todos ellos se determinó la reducción de algunas estructuras de las glándulas submandibulares, en ratas. Así tenemos, a Noorafshan, quien observó una disminución del volumen total de los conductos contorneados granulares y de los acinos serosos en ratas, a las cuales se les indujo hipotiroidismo mediante la administración de metimazol. Este mismo autor, en 2006, produjo diabetes en ratas por medio de estreptozotocina, señalando la reducción del volumen total de los acinos serosos. Buyuk et al. (2015), determinaron un descenso del área de los acinos seromucosos y de los conductos contorneados granulares, en ratas postmenopáusicas (por extirpación ovárica) y diabéticas (por administración de aloxano). Ali (2018), también indujo diabetes en ratas, mediante el aloxano, y observó una mejora del volumen medio de los acinos de las glándulas submandibulares luego del tratamiento con ozono y con ozono más insulina, mientras que no lo hubo con la administración única de insulina. La desnutrición proteica ha sido también estudiada, estereológicamente, en ratones Swiss, en los cuales se encontró una disminución de la $\mathrm{V}_{\mathrm{v}}$ de los conductos a un $27,5 \pm 1,68 \%$. En todos estos casos, el déficit hormonal o de la materia prima que se necesitan, como factores inductores del crecimiento y desarrollo de estas estructuras, debieron haber influenciado en el resultado.

Otros trabajos morfométricos y estereológicos se han dedicado a observar los efectos nocivos de algunas sustancias, en las glándulas submandibulares de ratas. Mahmoudzadeh-Sagheb et al., estudiaron los efectos, de la aplicación de Litio, en la morfología de las glándulas submandibulares de ratas, observando la reducción de densidad de volumen y volumen total de los acinos de los conductos contorneados granulosos y de los estriados, así como un aumento del estroma conectivo. Tirapelli et al. (2001) y Andreo et al. (2008), utilizaron ratas para observar el efecto deletéreo de la suministración crónica de alcohol, en las diferentes estructuras de la glándula submandibular. Aquí po- 
dría deducirse una acción tóxica de estas sustancias, lo cual interfirió en el normal crecimiento de la glándula.

El campo de la experimentación en modelos animales necesita adquirir un conocimiento más profundo acerca de la morfología y fisiología de sus órganos, lo que permitirá llevar a cabo análisis comparativos más fidedignos, con la especie humana y entre sanos y enfermos. El estudio que hemos presentado nos indica, de forma cuantitativa, las proporciones porcentuales, cantidades por área y por volúmenes, tanto de los conductos, como de las células acinares que forman parte de las glándulas submandibulares de ratones (Mus musculus) C57BL/6 macho, con lo cual se pretende determinar la normalidad en este modelo experimental y sentar las bases para futuros estudios.

OCAMPO, J.; VÁSQUEZ, B.; SANDOVAL, C.; NAVARRETE, J.; HAIDAR, Z. S. \& OLATE, S. Morphocuantitative characteristics of the mouse (Mus musculus) submandibular gland. Int. J. Morphol., 38(3):570$577,2020$.

SUMMARY: The mouse (Mus musculus) is a good experimental animal model, where murine salivary glands have been widely used in research by their similarities with human glands. Stereology is a tool that has to demonstrated to be valuable in biomedical researc $h$. Therefore, the objective was to realize an analogy between morphology, function and morpho-quantitative characteristics of the C57BL/6 mouse submandibular gland. Five male mice, C57BL/6, from 11 to 13 weeks old were used, with an average weight of $30 \mathrm{~g}$. After seven days, the mice were euthanized and the samples were extracted. Then, these were processed following the conventional histological processing protocol and stained with H\&E, Picrosirius Red, AA and PAS. Finally, the histological and stereological analysis of the samples was performed. In the glandular ducts the length density $\left(\mathrm{L}_{\mathrm{V} \text { cond }}\right)$, volume density $\left(\mathrm{V}_{\mathrm{Vcond}}\right)$ and surface density $\left(\mathrm{S}_{\mathrm{Vcond}}\right)$ were determined; whereas, in the acinar cells the density of number $\left(\mathrm{N}_{\mathrm{vcel}}\right)$ and the density of volume $\left(\mathrm{V}_{\mathrm{Vcel}}\right)$ were evaluated. For each stereological variable the mean \pm standard deviation was obtained. The histological study revealed no discrepancies as previously described. Descriptive statistical analysis revealed the following: $\mathrm{L}_{\mathrm{V} \text { cond }}=220.02 \pm 50.51 \mathrm{~mm} / \mathrm{mm}^{3} ; \mathrm{VV}$ cond $=50.48$ $\pm 9.55 \% ; \mathrm{SV}$ cond $=26.39 \pm 5.45 \mathrm{~mm}^{2} / \mathrm{mm}^{3} ; \mathrm{N}_{\mathrm{Vcel}}=168467.38$ $\pm 91288.67 / \mathrm{mm}^{3}$ and $\mathrm{V}_{\mathrm{v}_{\text {cel }}}=24.98 \pm 6.22 \%$. From this study, it will be possible to conduct comparative experimental research analyzing quantitative results from those presented in this research. From this study, it will be possible to carry out comparative experimental research, analyzing quantitative results from those presented in this investigation.

KEYWORDS: Submandibular Gland; Mouse; Histology; Morpho-quantitative analysis; Stereology.

\section{REFERENCIAS BIBLIOGRÁFICAS}

Ali, S. Y.A. Stereological and immunohistochemical study on the submandibular gland of diabetic albino rats. J. Am. Sci., 14(12):24-33, 2018.

Amano, O. \& Iseki, S. Cell growth factors in salivary glands. Microscope, 40:1-6, 2005.

Amano, O. \& Iseki, S. Expression and localization of cell growth factors in the salivary gland: a review. Acta Anat. Nippon., 71:201-11, 2001.

Amano, O. The salivary gland: anatomy for surgeons and researchers. Jpn. J. Oral Maxillofac. Surg., 57:384-93, 2011.

Amano, O.; Mizobe, K.; Bando, Y. \& Sakiyama, K. Anatomy and histology of rodent and human major salivary glands: Overview of the Japan Salivary Gland Society-Sponsored Workshop. Acta Histochem. Cytochem., 45(5):241-50, 2012.

Andreo, J. C.; Rodriguez, A. C.; Silva, F. B.; Rosa-Júnior, G. M.; Moraes, L. H. R. \& Sousa, S. G.M. Histomorfometria da glândula submandibular de rato (Rattus Novergicus) submetidos à dieta alcoólica - Parte II. Cienc. Odontol. Bras., 11(1):42-8, 2008.

Beura, L. K.; Hamilton, S. E.; Bi, K.; Schenkel, J. M.; Odumade, O. A.; Casey, K. A.; Thompson, E. A.; Fraser, K. A.; Rosato, P. C.; FilaliMouhim, A.; Sekaly, R. P.; Jenkins, M. K.; Vezys, V.; Haining, W. N.; Jameson, S. C. \& Masopust, D. Normalizing the environment recapitulates adult human immune traits in laboratory mice. Nature, 532:512-6, 2016.

Buyuk, B.; Parlak, S. N.; Keles, O. N.; Can, I.; Yetim, Z.; Toktay, E.; Selli, J. \& Unal, B. Effects of diabetes on post-menopausal rat submandibular glands: a histopathological and sterelogical examination. Eurasian J. Med., 47:199-207, 2015.

Carlson, E. R. \& Ord, R. Salivary Gland Pathology: Diagnosis and Management. 2da ed. Hoboken-New Jersey, Wiley-Blackwell, 2015.

Chen, S.; Gao, F.; Kotani, A. \& Nagata, T. Age-related changes of male mouse submandibular gland: a morphometric and radioautographic study. Cell. Mol. Biol. (Noisy-le-grand), 41:117-24, 1995.

Dawes, C.; Pedersen, A. M. L.; Villa, A.; Ekström, J.; Proctor, G. B.; Vissink, A.; Aframian, D.; McGowan, R.; Aliko, A.; Narayana, N.; Sia, Y. W.; Joshi, R. K.; Jensen, S. B.; Kerr, A. R. \& Wolff, A. The functions of human saliva: A review sponsored by the World Workshop on Oral Medicine VI. Arch. Oral Biol., 60(6):863-74, 2015.

de Asis, G. F.; Cestari, T. M.; Stipp, A. C. M.; Hassunuma, R. M. \& Taga, R. A morphometric study of seasonal influences on the daily cycle of rat submandibular glands. Braz. J. Morphol. Sci., 17:93-100, 2000.

de Paula, F.; Teshima, T. H. N.; Hsieh, R.; Souza, M. M.; Nico, M. M. S. \& Lourenco, S.V. Overview of human salivary glands: Highlights of morphology and developing processes. Anat. Rec. (Hoboken), 300(7):1180-8, 2017.

Denny, P. C.; Ball, W.D. \& Redman, R. S. Salivary glands: a paradigm for diversity of gland development. Crit. Rev. Oral Biol. Med., 8(1):51$75,1997$.

Flavia, R.; Gal, A. F.; Matosz, B.; Luca, V. E. \& Micla u?, V. Comparative stereological study of the striated and granular ducts in mouse and rat mandibular glands. Agriculture-Science and Practice, 3-4(103104):120-25, 2017.

Gresik, E. W. The granular convoluted tubule (GCT) cell of rodent submandibular glands. Microsc. Res. Tech., 27(1):1-24, 1994.

Gresik, E. W.; Hosoi, K.; Kurihara, K.; Maruyama, S. \& Ueha, T. The rodent granular convoluted tubule cell - an update. Eur. J. Morphol., 34(3):221-4, 1996.

Jacob, S. \& Lawrence, A. G. Effects of protein malnutrition on the mouse submandibular gland. J. Anat., 165:169-75, 1989.

Kondo, Y.; Saruta, J.; To, M.; Shiiki, N.; Sato, C. \& Tsukinoki, K. Expression and role of the BDNF receptor-TrkB in rat adrenal gland under acute immobilization stress. Acta Histochem. Cytochem., 43:139-47, 2010.

Korsrud, F. R. \& Brandtzaeg, P. Characterization of epithelial elements in human major salivary glands by functional markers: localization of amylase, lactoferrin, lysozyme, secretory component, and secretory 
immunoglobulins by paired immunofluorescence staining. $J$. Histochem. Cytochem., 30(7):657-66, 1982.

Lantini, M. S.; Cossu, M.; Isola, M; Piras, M. \& Piludu, M. Subcellular localization of epidermal growth factor receptor in human submandibular gland. J. Anat., 208(5):595-9, 2006.

Louveau, A.; Smirnov, I.; Keyes, T. J.; Eccles, J. D.; Rouhani, S. J.; Peske, J. D.; Derecki, N. C.; Castle, D.; Mandell, J. W.; Lee, K. S.; Harris, T. H. \& Kipnis, J. Structural and functional features of central nervous system lymphatic vessels. Nature, 523:337-41, 2015.

Mahajan, V. S.; Ezana Demissie, E.; Mattoo, H.; Viswanadham, V.; Varki, A.; Morris, R. \& Pillai, S. Striking immune phenotypes in diverse gene-targeted mice are driven by a copy number variant originating from a commercially available C57BL/6 strain. Cell Rep., 15(9):19019, 2016.

Mahmouzadeh-Sagheb, H. R.; Heidari, Z. \& Noori-Mugahi, M. H. A stereological study of the effects of lithium on morphology of submandibular gland. Pak. J. Biol. Sci., 9(4):746-49, 2006.

Mandarim-de-Lacerda, C. A. \& del Sol, M. Tips for studies with quantitative morphology (morphometry and stereology). Int. J. Morphol., 35(4):1482-94, 2017.

Mattioli, T. M. F.; Alanis, L. R. A.; da Silva Sapelli, S.; de Lima, A. A. S.; de Noronha, L.; Rosa, E. A. R.; Althobaiti, Y. S.; Almalki, A. H.; Sari, Y.; Ignacio, S. A.; Johann, A. C. B. R. \& Gregio, A. M. T. Effects of benzodiazepines on acinar and myoepithelial cells. Front. Pharmacol., 7:173, 2016.

Mori, M.; Takai, Y. \& Kunikata, M. Review: Biologically active peptides in the submandibular gland -role of the granular convoluted tubule. Acta Histochem. Cytochem., 25(1-2):325-41, 1992.

Nilsson, C.; Raun, K.; Yan, F. F.; Larsen, M. O. \& Tang-Christensen, M. Laboratory animals as surrogate models of human obesity. Acta Pharmacol. Sin., 33(2):173-81, 2012.

Noorafshan, A. Stereological study on the submandibular gland in hypothyroid rats. APMIS, 109:223-7, 2001.

Noorafshan, A. Volume-weighted mean volume of the submandibular gland acini in male and female diabetic rats. Micron, 37:613-16, 2006.

Ocampo, J.; Olate, S.; Haidar, Z. S. \& Vásquez, L. Hiposialia y xerostomía post irradiación: Terapias innovadoras en el campo biomolecular. Int. J. Morphol., 37(4):1564-71, 2019.

Pardini, L. C. \& Taga, R. Stereological study of the sexual dismorphism in mouse submandibular glands. Okajimas Folia Anat. Jpn., 73(2):11924, 1996.

Pinkstaff, C. A. Salivary gland sexual dimorphism: a brief review. Eur. $J$. Morphol., 36:31-4, 1998.

Reeves, P. G.; Nielsen, F. H. \& Fahey, G. C. AIN-93 purified diets for laboratory rodents: final report of the American Institute of Nutrition ad hoc writing committee on the reformulation of the AIN-76A rodent diet. J. Nutr., 123(11):1939-51, 1993.

Roa, I. \& del Sol, M. Parotid gland comparative microscopic anatomy. Int. J. Morphol., 37(2):701-5, 2019.

Sashima, M. Age-related changes of rat submandibular gland: a morphometric and ultrastructural study. J. Oral Pathol., 15:507-12, 1986.

Sato, A.; Goto, F. \& Miyoshi, S. Ultrastructure of the main excretory duct epithelium of the female mouse submandibular gland with special reference to sexual dimorphism. Cell Tissue Res., 277(3):407-15, 1994.

Suazo, G. I. C. \& Roa, H. I. J. Anatomía microscópica de las glándulas salivales por medio de una técnica histológica convencional y no convencional. Int. J. Morphol., 26(3):689-95, 2008.

Tirapelli, L. F.; Tirapelli, C. R.; Tirapelli, D. P. C.; Cassel. F. D.; Petroni, S. \& Tamega, O. J. Morphometric analysis of seromucous acini and granular ducts of submandibular glands from rats (Rattus norvegicus) submitted to experimental chronic alcoholism. Rev. chil. anat., 19(3):263-9, 2001.

Treuting, P. M.; Dintzis, S. M. \& Montine, K. S. Comparative Anatomy and Histology: A Mouse, Rat, and Human Atlas. 2da ed. London, Academic Press-Elsevier, 2018.
Vucicevic-Boras, V.; Topic, B.; Cekic-Arambasin, A.; Zadro, R. \& Stavljenic-Rukavina, A. Lack of association between burning mouth syndrome and hematinic deficiencies. Eur. J. Med. Res., 6(9):409-12, 2001.

Wu, H. H.; Kawamata, H.; Wang, D. D. \& Oyasu, R. Immunohistochemical localization of transforming growth factor alpha in the major salivary glands of male and female rats. Histochem. J., 25:613-8, 1993.

\author{
Dirección para correspondencia: \\ Dra. Bélgica Vásquez \\ Universidad de Tarapacá \\ Arica \\ CHILE
}

Email: bvasquezp@uta.cl

Recibido : 14-12-2019

Aceptado: 22-01-2020 